\title{
Criação e trajetória inicial do Programa de Pós-Graduação em Psicologia da UFPI
}

\author{
Ludgleydson Fernandes de Araújo. Universidade Federal do Delta do Parnaíba \\ Emerson Diógenes de Medeiros. Universidade Federal do Delta do Parnaíba \\ Fauston Negreiros. Universidade Federal do Delta do Parnaíba \\ João Paulo Macedo. Universidade Federal do Delta do Parnaíba \\ Paloma Cavalcante Bezerra de Medeiros. Universidade Federal do Delta do Parnaíba \\ Raquel Pereira Belo. Universidade Federal do Delta do Parnaíba \\ Sandra Elisa de Assis Freire. Universidade Federal do Delta do Parnaíba
}

\section{Resumo}

Trata-se de um relato sobre a criação e a trajetória inicial do Programa de Pós-Graduação em Psicologia na UFPI, com base em um levamento documental. Implantado na cidade de Parnaíba-PI, desde abril de 2017, ressalta-se que é o único PPG em Psicologia do estado, possibilitando psicólogos e demais profissionais articularem o desenvolvimento científico e a produção do conhecimento na região. Com área de concentração em Psicologia, conta com 10 docentes permanentes distribuídos em duas linhas de pesquisa: 1) Processos psicossociais e sua avaliação em diferentes contextos; 2) Psicologia, Saúde Coletiva e Processos de subjetivação e 55 discentes com matrícula ativa e 13 egressos. A análise considerou as atividades desenvolvidas, dificuldades e desafios com base nos caminhos e desafios postos à pós-graduação brasileira. Conclui-se no empenho do PPGPsi para sua consolidação na pesquisa e ensino da pós-graduação, na formação de recursos humanos e no impacto social.

Palavras chave: pós-graduação; psicologia; pesquisa; interiorização; história.

\section{Abstract}

Creation and initial trajectory of the Post-graduation Program in Psychology at UFPI. This is an account of the creation and initial trajectory of the Graduate Program in Psychology at UFPI, based on a documentary background. Implemented in the city of Parnaíba$\mathrm{PI}$, since April 2017, it is noteworthy that is the only PPG in Psychology of the state, enabling psychologists and other professionals to articulate scientific development and knowledge production in the region. With a concentration area in Psychology, it has 10 permanent professors distributed in two research lines: 1) Psychosocial processes and their evaluation in different contexts; 2) Psychology, Collective Health and Subjectivation Processes and 55 students with active enrollment and 13 graduates. The analysis considered the activities developed, difficulties and challenges based on the paths and challenges posed to the Brazilian graduate. It concludes PPGPsi's commitment to its consolidation in postgraduate research and teaching, human resources training and social impact. Keywords: post-graduation; psychology; research; interiorization; history.

\section{Resumen}

Creación y trayectoria inicial del Programa de Posgrado en Psicología de la UFPI. Este es un relato de la creación y la trayectoria inicial del Programa de Posgrado en Psicología en la UFPI, basado en antecedentes documentales. Implementado en la ciudad de Parnaíba-PI, desde abril de 2017, es notable que sea el único PPG en Psicología del estado, lo que permite a los psicólogos y otros profesionales articular el desarrollo científico y la producción de conocimiento en la región. Con un área de concentración en Psicología, cuenta con 10 profesores permanentes distribuidos en dos líneas de investigación: 1) Procesos psicosociales y su evaluación en diferentes contextos; 2) Procesos de psicología, salud colectiva y subjetivación y 55 estudiantes con matrícula activa y 13 egresos. El análisis consideró las actividades desarrolladas, las dificultades y los desafíos basados en los caminos y desafíos planteados al graduado brasileño. Concluye el compromiso de PPGPsi con su consolidación en investigación y enseñanza de posgrado, capacitación en recursos humanos e impacto social.

Palabras claves: postgrado; psicología; la investigación; interiorización; historia. 
Neste artigo será abordado o contexto de criação e a trajetória inicial de um dos Programas de Pós-Graduação em Psicologia (PPGPsi) mais recente do Nordeste brasileiro, localizado, inclusive, fora de capitais dos estados, na perspectiva de avançar na redução das assimetrias da área no território nacional. Trata-se do PPGPsi da Universidade Federal do Piauí (UFPI), no Campus Ministro Reis Velloso (CMRV), localizado na região litorânea do Estado do Piauí, na cidade de Parnaíba. Para isto será apresentado, inicialmente, o percurso histórico de constituição do Programa, discorrendo desde a implantação do curso de graduação em Psicologia na UFPI, passando pela chegada do corpo docente de diversas universidades brasileiras e a necessidade de um espaço para o desenvolvimento do ensino e da pesquisa no âmbito da pós-graduação stricto sensu no estado do Piauí. Em seguida, destacar-se-á as atividades desenvolvidas e as dificuldades enfrentadas na realidade de um Programa de Pós-Graduação recém-criado, diante de uma conjuntura difícil que enfrenta a educação e a ciência e tecnologia no país e do próprio contexto de criação da Universidade Federal do Delta do Parnaíba (UFDPar), por meio da Lei N 13.651/2018, a partir do desmembramento do CMRV da UFPI. Por fim, discorreremos acerca dos desafios com base nos horizontes trilhados pela pós-graduação brasileira.

Em termos metodológicos, trata-se de um relato histórico apoiado nos documentos institucionais da própria UFPI (Plano de Desenvolvimento Institucional PDI), do Projeto Político Pedagógico do curso de Psicologia e do Projeto de Criação do PPGPsi, acompanhado dos respectivos relatórios de gestão, além da consolidação das informações acerca da Avaliação de Meio Termo realizada para Comissão da Área de Psicologia da Coordenação de Aperfeiçoamento de Pessoal de Nível Superior (CAPES) em meados de 2019.

\section{Contexto histórico de criação e perfil dos docentes do Programa de Pós-Graduação em Psicologia (UFPI)}

A UFPI foi criada em 1968 e oficialmente instalada em 1971. Ao longo da sua trajetória a UFPI tem avançado na área de formação de recursos humanos e da pesquisa científica no estado do Piauí. Especificamente na Pós-Graduação, conta com 47 programas, sendo 17 Doutorados (15 Institucionais e 02 em Rede), 43 Mestrados Acadêmicos e 07 Mestrados Profissionais, totalizando 67 cursos (CAPES, 2019).
O projeto de expansão das Universidades Federais nos Governos do Partido dos Trabalhadores, por meio dos Programas Expandir I e Reuni, trouxe para a UFPI a realidade multicampi, respondendo as necessidades de formação de pessoal e de produção de conhecimento, observando as especificidades loco-regionais do estado, bem como a demanda para a formação pós-graduada. Com a expansão, a UFPI ganhou maior capacidade para interiorizar-se pelo estado do Piauí. Além da cidade de Parnaíba, cujo campus data da fundação da própria UFPI, apesar de ter ganhado nova estrutura física e incremento do quadro docente e técnico-administrativo, novos campi universitários foram instalados nas cidades de Floriano, Picos e Bom Jesus, todas localizadas na região sul do estado (UFPI, 2015).

Foi neste contexto que em 2007 foi instalado o curso de Psicologia no CMRV. Parnaíba é uma cidade polo de desenvolvimento regional com importância econômica, turística e no setor de serviços das áreas de saúde e educação, para cerca de 30 municípios localizados no norte dos estados do Piauí, Maranhão e Ceará. Além do curso de Psicologia, o CMRV conta com os Cursos de Administração, Economia, Ciências Contábeis, Pedagogia, Engenharia de Pesca, Turismo, Matemática, Biologia, Biomedicina, Fisioterapia e Medicina.

A proposta de criação do primeiro PPGPsi do Estado do Piauí surgiu 10 anos após a criação do curso de graduação em Psicologia. Nesse meio tempo, o curso de Psicologia reuniu um conjunto de condições que garantiu o êxito da aprovação do Projeto com a Avaliação de Propostas para Cursos Novos (APCN), em 2016, sendo que a abertura oficial do Programa aconteceu em abril de 2017. Destaca-se, nesse sentido, a qualificação do quadro de professores do Departamento de Psicologia da UFPI que passou a contar com 25 docentes, sendo que a grande maioria possuía doutorado. Registra-se a colaboração inicial de três professores vinculados ao curso de Medicina, com formação graduada e/ou pós-graduada em Psicologia, ministrando disciplinas de graduação e orientando alunos de iniciação científica no curso de Psicologia.

Parte deste corpo docente, apoiado pela administração do Campus, começou a desenvolver atividades colaborativas e de intercâmbio e cooperação acadêmico-científica e passou a contar com espaços de núcleos de pesquisa para o desenvolvimento de estudos na área, dentre os quais se destacam temas de estudo e investigação em psicologia social e do desenvolvimento, avaliação psicológica, neuropsicologia, relações de trabalho 
e organizações, saúde, educação, assistência social e demais políticas públicas, formação do psicólogo, relações de gênero e étnico-raciais, questões ambientais e territoriais, comunidades e povos tradicionais.

Como parte do planejamento para a construção da Proposta, alguns entre os professores do curso de Psicologia obtiveram aprovação de recursos financeiros para o desenvolvimento de atividades de pesquisa e/ou extensão, provenientes de órgãos de fomento, tais como FINEP (Financiadora de Inovação e Pesquisa), CNPq (Conselho Nacional de Desenvolvimento Científico e Tecnológico), CAPES, FAPEPI (Fundação de Amparo a Pesquisa do Estado do Piauí), além do Ministério da Educação, Ministério da Saúde e outras fontes de financiamento. Por meio dos projetos de pesquisa e/ou extensão aprovados, os professores têm se nucleado em linhas de pesquisas estratégicas para o desenvolvimento de estudos em Psicologia, fortalecendo as atividades de ensino, pesquisa e extensão, sempre em consonância com as necessidades regionais em que estão inseridos. Ademais, pelo menos cinco professores ingressaram em Programas de Pós-Graduação da própria UFPI e de outras IFES do Nordeste brasileiro, a exemplo da Universidade do Vale do São Francisco (UNIVASF), ampliando e aprimorando ainda mais suas experiências em pesquisa, docência e orientação de trabalhos acadêmicos, além da interface da Psicologia com outras áreas do conhecimento (UFPI, 2016).

Aliado a isso havia a necessidade de fortalecer a formação pós-graduada, nível stricto sensu, no estado do Piauí, para responder tanto a demanda dos egressos do curso de Psicologia da UFPI, em Parnaíba, quanto dos demais cursos de Psicologia do Estado ( $n=11$ ) (Câmara dos Deputados, 2018), inclusive dos docentes das demais Instituições de Ensino Superior e profissionais em geral. O Piauí, até então, era o único estado do Nordeste que não contava com Programa de Pós-Graduação na área de Psicologia (CAPES, 2018).

Neste sentido, a abertura do Curso de Mestrado na UFPI, em Parnaíba, possibilitou a redução da demanda reprimida e a dependência de futuros alunos que buscavam formação pós-graduada fora do Estado (UFPI, 2016). Não obstante, pelo fato de estar sediado na cidade de Parnaíba, a abertura do PPGPsi, reforçaria o processo de interiorização da Pós-Graduação em Psicologia no Nordeste brasileiro, ainda embrionário, pois até o ano de 2016 havia somente dois cursos acadêmicos funcionando em localidades fora das capitais: PPG em Psicologia da Saúde na Universidade Estadual da Paraíba - UEPB, localizado no município de Campina Grande-PB; PPG em Psicologia na UNIVASF, localizado no município de Petrolina-PE (CAPES, 2016).

Para a construção da proposta do Programa foi constituída Comissão de Elaboração da Proposta de Criação do Mestrado em Psicologia da UFPI, por meio da Portaria n. ${ }^{\circ} 23$ da Pró-Reitoria de Ensino de Pós-Graduação, de 07 de outubro de 2015, composta pelos professores João Paulo Sales Macedo, Fauston Negreiros, Ludgleydson Fernandes de Araújo, Raquel Pereira Belo e Ana Kalliny de Sousa Severo (UFPI, 2015), bem como houve a inclusão da referida Proposta no Plano de Desenvolvimento Institucional (PDI) da Universidade Federal do Piauí (UFPI, 2016). O trabaIho da Comissão contou na etapa final de elaboração da Proposta com o apoio e assessoria dos Professores Oswaldo Hajime Yamamoto (PPGPsi) - titular da Universidade Federal do Rio Grande do Norte (UFRN) e Antônio Virgílio Bittencourt Bastos (PPGPsi) - titular da Universidade Federal da Bahia (UFBA) e Coordenador de Área da CAPES à época. A versão final da proposta seguiu para aprovação do projeto no âmbito da UFPI, por meio da Resolução $N^{\circ} 73$, de 15 de abril de 2016, do Conselho de Ensino, Pesquisa e Extensão (CEPEX) (UFPI, 2016) e posterior submissão e aprovação na CAPES, por meio da $166^{\text {a }}$ Reunião CTC (CAPES, 2018). As atividades do PPGPSI da UFPI foram oficialmente iniciadas em 17 de abril de 2017, com a aula inaugural "Pós-Graduação em Psicologia no Brasil: rumos e perspectivas", ministrada pelo Prof. Antônio Virgílio Bittencourt Bastos (PPGPsi -UFBA).

Ressalta-se nesse sentido, que a criação do PPGPsi UFPI é fruto da própria consolidação do sistema de pós-graduação nacional nas últimas décadas, impulsionado pela formação qualificada de docentes-pesquisadores que ingressaram na rede federal de ensino superior nesse período, sob o contexto da expansão e interiorização do ensino superior brasileiro, apoiados ainda por um maior incremento do financiamento à pesquisa pelas agências de fomento nacionais e internacionais, resultando assim na criação de novos programas, reduzindo as simetrias regionais, por meio da interiorização da pós-graduação (Alves \& Oliveira, 2014).

Do ponto de vista da área de Psicologia na CAPES, mesmo alcançando o patamar de 92 Programas, sendo 57 de Mestrado/Doutorado, 28 de Mestrado e 07 de Mestrado Profissionalizante (CAPES, 2019), indicando certa descentralização e o êxito do crescimento de Programas nas regiões Norte, Centro-Oeste e,

Estudos de Psicologia, 24(2), abril a junho de 2019, 136-146 
especialmente, no Nordeste, o diagnóstico realizado por Féres-Carneiro et al (2010) de que enfrentamos uma alta "concentração de Programas em alguns estados e numa região do país", ainda se mantém, considerando a "própria história da construção do ensino superior, da pesquisa e da própria Pós-Graduação no Brasil" (p. 23).

\section{Atividades desenvolvidas e as dificuldades enfrentadas na realidade de um Programa de Pós-Graduação recém-criado}

O PPGPSi da UFPI conta atualmente com 10 docentes (ver Quadro 1), sendo todos do quadro permanente, com área de concentração em Psicologia e duas linhas de pesquisa, a saber: 1) Processos psicossociais e sua avaliação em diferentes contextos; e 2) Psicologia, Saúde Coletiva e Processos de subjetivação. É importante mencionar que o tamanho do corpo docente do PPGPsi da UFPI não se distancia substancialmente dos dados apresentados pela Associação Nacional de Pesquisa e Pós-Graduação em Psicologia (ANPEPP) no Seminário do Meio de Termo em Salvador-BA, neste ano de 2019, em que existe uma média de 14,69 de professores permanentes nos PPGPsi no biênio 2017-2018 (CAPES, 2019). Neste sentido, é importante conhecer o perfil dos docentes que estão construindo esta história recente do Programa com as dificuldades e desafios no fazer ensino e pesquisa no âmbito da pós-graduação (stricto sensu) no interior do Nordeste brasileiro em um contexto que até então não havia construído a tradição do fazer investigação científica.

Tabela 1. Linhas e Núcleos de Pesquisas do PPGPsi da UFPI

\begin{tabular}{|c|c|c|c|}
\hline Linhas de Pesquisa & Professor(a) & Nome do Núcleo & Descrição dos Temas de Pesquisa \\
\hline \multirow{14}{*}{$\begin{array}{l}\text { LINHA } 1 \\
\text { Processos psicossociais } \\
\text { e sua avaliação em } \\
\text { diferentes contextos }\end{array}$} & Oliveira & $\begin{array}{l}\text { Avaliação Psicológica } \\
\text { e Educação. }\end{array}$ & $\begin{array}{l}\text { Necessidades educacionais especiais. Transtornos depressivos. Transtorno de } \\
\text { ansiedade. Processos Psicológicos Básicos. Psicologia Cognitivo e Comportamental. }\end{array}$ \\
\hline & Emerson & Laboratório de Avaliação & Avaliação Psicológica, construção e adaptação de instrumentos de medidas \\
\hline & Diógenes de & Psicológica do Delta/Labap & em Psicologia, baseados em modelos psicométricos (TCT e TRI). Pesquisas \\
\hline & Medeiros & & $\begin{array}{l}\text { básicas e aplicadas em Psicologia Social. Personalidade e seus correlatos. } \\
\text { Comportamentos antissociais (bullying, comportamentos agressivos, uso e } \\
\text { abuso de Álcool e drogas, etc). Psicologia das diferenças individuais. }\end{array}$ \\
\hline & Fauston & Núcleo de Pesquisas em & Psicologia Escolar e Psicologia Histórico-Cultural. Psicologia, políticas \\
\hline & Negreiros & $\begin{array}{l}\text { Desenvolvimento Humano, } \\
\text { Psicologia Educacional e }\end{array}$ & $\begin{array}{l}\text { educacionais e processos de escolarização. Atuação e formação do psicólogo } \\
\text { escolar em uma perspectiva crítica. Processos de Medicalização na Educação. }\end{array}$ \\
\hline & & Queixa Escolar/PSIQUED & Psicologia Escolar em Contextos Emergentes. \\
\hline & Paloma & Laboratório de & Compreende estudos em Avaliação Neuropsicológica de Processos Psicológicos \\
\hline & Cavalcante & Neurociência e & Básicos, que buscam conhecer os mecanismos neuropsicológicos e \\
\hline & Bezerra de & Psicologia Social. & neurofisiológicos dos referidos processos, relacionando-os ao comportamento \\
\hline & Medeiros & & $\begin{array}{l}\text { social de indivíduos em condições normais, adversas ou apresentando } \\
\text { transtorno psiquiátrico. Além de realizar pesquisas em Psicologia Clínica, } \\
\text { considerando o modelo teórico da abordagem Cognitivo Comportamental. }\end{array}$ \\
\hline & Raquel Pereira & Núcleo de Pesquisas & Processos psicossociais do trabalho em contextos organizacionais. \\
\hline & Belo & $\begin{array}{l}\text { em Análise Psicossocial } \\
\text { do Trabalho e das } \\
\text { Organizações }\end{array}$ & $\begin{array}{l}\text { Comportamento organizacional e relações do indivíduo com o contexto em que } \\
\text { atua. Temáticas relativas ao mundo do trabalho e das organizações na atualidade. }\end{array}$ \\
\hline & $\begin{array}{l}\text { Sandra Elisa de } \\
\text { Assis Freire }\end{array}$ & $\begin{array}{l}\text { Núcleo de Pesquisa } \\
\text { em Relacionamento }\end{array}$ & $\begin{array}{l}\text { Investigar sobre os efeitos das emoções positivas no contexto da dinâmica das } \\
\text { relações familiares, do casamento contemporâneo e relacionamentos amorosos. }\end{array}$ \\
\hline
\end{tabular}


Tabela 1. Continuação

\begin{tabular}{|c|c|c|c|}
\hline Linhas de Pesquisa & Professor(a) & Nome do Núcleo & Descrição dos Temas de Pesquisa \\
\hline \multirow{5}{*}{$\begin{array}{l}\text { LINHA } 2 \\
\text { Psicologia, Saúde } \\
\text { Coletiva e Processos de } \\
\text { subjetivação }\end{array}$} & $\begin{array}{l}\text { Antônio } \\
\text { Vladimir Félix da }\end{array}$ & $\begin{array}{l}\text { Núcleo de Estudos e Pesquisas } \\
\text { em Análise Institucional e }\end{array}$ & Esquizonálise, cartografia dos processos de subjetivação em arte e educação da \\
\hline & Silva & Cartografia da Diferença & $\begin{array}{l}\text { e de grupos institucionais e comunitários, tais como: pessoas em situação de rua; } \\
\text { comunidade LGBTT, feminismos e transfeminismos; RENAFRO Saúde; pessoas } \\
\text { em situação de cárcere; jovens no cumprimento de medidas socioeducativas; } \\
\text { profissionais de saúde; familiares e usuários da Rede de Atenção Psicossocial. }\end{array}$ \\
\hline & João Paulo Sales & Núcleo de Estudos e & Discutir o trabalho e a formação do psicólogo no âmbito das políticas públicas \\
\hline & Macedo & $\begin{array}{l}\text { Pesquisas em Psicologia, } \\
\text { Políticas Públicas e } \\
\text { Subjetivação }\end{array}$ & $\begin{array}{l}\text { e em cenários de vulnerabilidade social; investigar as formas de aproximação } \\
\text { entre psicologia, territórios rurais, povos e comunidades tradicionais; realizar } \\
\text { estudos que reflitam sobre modos de vida, ruralidades, interseccionalidades e } \\
\text { subjetivação política. }\end{array}$ \\
\hline & $\begin{array}{l}\text { Lana Veras } \\
\text { de Carvalho }\end{array}$ & $\begin{array}{l}\text { Núcleo de Estudos e Pesquisas } \\
\text { em Psicologia, Políticas }\end{array}$ & $\begin{array}{l}\text { Psicologia social em saúde. Processos psicossociais em saúde. Perda, luto e } \\
\text { subjetividade contemporânea. Mercantilização e patologização do luto. }\end{array}$ \\
\hline
\end{tabular}

Destaca-se que no perfil dos professores do PPGPsi conta-se com dois professores com doutoramento obtido entre 2000-2009 (20\%) e os demais obtido entre 2010-2014 (70\%). Portanto, um corpo docente jovem e oriundo de Programas de Pós-Graduação e áreas de concentração diversificadas, a saber: Universidade Federal da Paraíba (Área de concentração: Psicologia Social), Universidade Federal do Rio Grande do Norte (Área de concentração: Psicologia), Universidade Federal do Ceará (Área de concentração: Educação), Universidade Estadual do Rio de Janeiro (Área de concentração: Psicologia Social), Universidade de Granada/Espanha (Área de concentração: Psicologia) e Universidade de Havana/Cuba (Área de concentração: Ciências Psicológicas). Trata-se, portanto, de uma configuração que espelha a realidade da área na CAPES, considerando a abrangência da grande maioria dos Programas, devido as características do próprio perfil do seu corpo docente (Tourinho \& Bastos, 2010).
Do ponto de vista das ações de articulação e cooperação acadêmica, seguindo a tendência nacional e internacional na realização de pesquisas científicas em rede com a troca de experiências com outras instituições de ensino superior, o PPGPsi da UFPI possui intercâmbios interinstitucionais com grupos de pesquisa e demais Programas de Pós-Graduação em Psicologia e áreas afins. Estas redes surgiram de pesquisas e missões acadêmicas realizadas em conjunto com grupos de pesquisa no Brasil (ver Figura 1) e no exterior (ver Figura 2): as referidas figuras apresentam o quantitativo de instituições parceiras nos intercâmbios nacionais e internacionais dos docentes do PPGPSI/UFPI. É sabido que a mediação destas parcerias tem como locus os Grupos de Trabalho da ANPEPP, e o próprio histórico de formação dos docentes em instituições localizadas, especialmente, no Nordeste do país e no exterior.

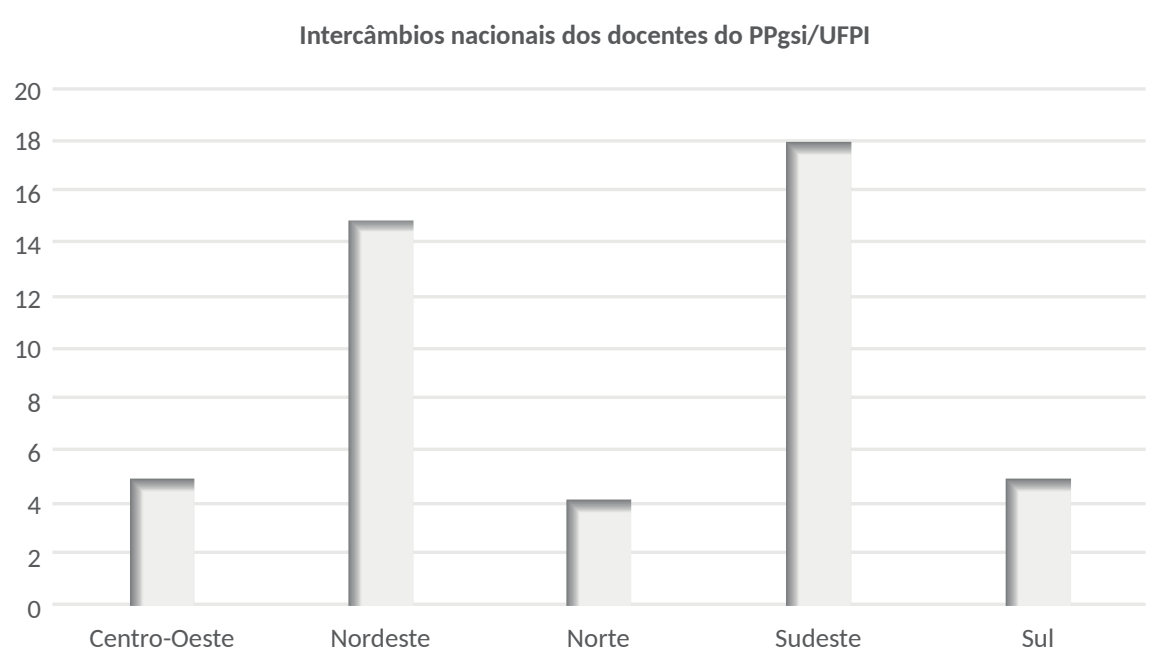

Figura 1. Quantitativo de Instituições Parceiras nos Intercâmbios Nacionais dos Docentes do PPGPSI/UFPI. 


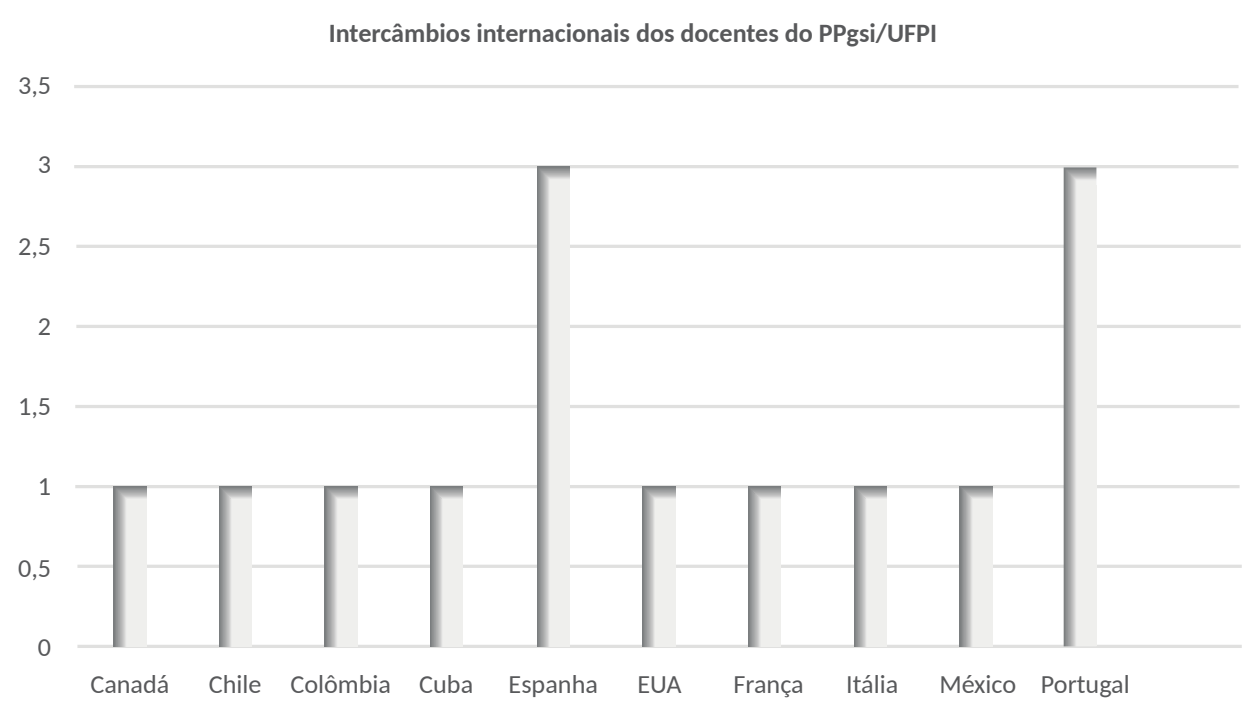

Figura 2. Quantitativo de Instituições Parceiras nos Intercâmbios Internacionais dos Docentes do PPGPSI/UFPI.

O fortalecimento dessas redes potencializa a qualificação do próprio sistema da área de Psicologia com a consolidação de laços entre Programas e entre pesquisadores, inclusive aproximando Programas novos com Núcleos de excelência ou com Programas mais consolidados, resultando em fortes impactos na produção científica nacional (Tourinho \& Bastos, 2010). Especificamente no caso do PPGPsi da UFPI, tais parcerias com demais Programas de Universidades brasileiras e estrangeiras têm contribuído para a consolidação dos grupos/núcleos de pesquisa com a participação em bancas de defesas de mestrados e doutorados, nas publicações de artigos em revistas com Qualis CAPES, de renome nacional e internacional, bem como na organização de livros/coletâneas sobre temas relativos as linhas e núcleos de pesquisas, o que tem colocado em evidência nossas pesquisas no âmbito da pós-graduação.

No que diz respeito aos Intercâmbios Internacionais, os docentes do PPGPsi possuem parcerias com instituições latino-americanas, norte-americanas e europeias para a estruturação e consolidação dos grupos/núcleos de pesquisa na UFPI, sinalizando uma preocupação para o desenvolvimento de ações no âmbito da internacionalização, tanto do ponto de vista da publicação em revistas de circulação internacional, quanto da mobilidade de docentes do Programa em centros de pesquisa estrangeiros, assim como com o recebimento de pesquisadores estrangeiros para as atividades de ensino e pesquisa do PPGPsi.
Além disso, é importante destacar que a participação do corpo discente no PPGPsi é uma parte igualmente relevante no labor de fazer pesquisa na pós-graduação (stricto sensu) no interior do Nordeste brasileiro. A presença do PPGPsi nesta região tem despertado nos profissionais psicólogos e áreas afins a necessidade da qualificação com experiências de temáticas psicossociais com relevância social e acadêmica. Desde o seu início, os discentes são distribuídos em alunos recém-egressos dos cursos de Psicologia de diferentes IES do Estado do Piauí e demais localidades do país, como também daqueles que trabalham em instituições, como docentes, seja do ensino superior, seja do ensino regular. Ressalta-se ainda, que o Programa, além de atender prioritariamente os egressos do curso de Psicologia, também atende discentes egressos de cursos da área de Ciência Humanas e Sociais e da área da Saúde.

Quanto ao processo formativo dos discentes, o PPGPsi da UFPI empenha-se para que estes sejam capazes de identificar problemas de investigação e desenvolver pesquisas com relevância social e científica; formular proposta de investigação em consonância com os desafios da ciência contemporânea, respeitando os princípios éticos que norteiam a prática científica; desenvolver senso crítico e responsável acerca da realidade social em que está inserido, bem como os diferentes níveis de análise do "fenômeno psicológico", considerando a multiplicidade dos objetos e das abordagens teóricas e metodológicas; comunicar de forma competente o conhecimento 
produzido; atuar no âmbito do ensino superior, inovando a prática docente, de modo a colaborar com o desenvolvimento científico e a produção do conhecimento da área; demonstrar capacidade de reflexão crítica no âmbito da docência e da pesquisa.

Atualmente o Programa possui 55 alunos ativos e 13 egressos. Destes, identifica-se seis que se encontram no exercício da docência que abrange o ensino superior em instituições pública e privada, o ensino técnico e em pós-graduações lato sensu. Ainda se observa que sete estão trabalhando em instituições diversas, no âmbito público e privado, desenvolvendo atividades diversas, a saber: psicólogo atuando na rede de serviços do Sistema Único de Saúde e do Sistema Único da Assistência Social; egressos de Programas de Residências em Psicologia e Multiprofissional em Saúde; psicólogo escolar; psicólogo atuando na assistência estudantil da Rede Federal do Ensino Superior (Universidades Federais e Institutos Federais); psicólogo atuando na educação na produção de material para o ensino de robótica na educação infantil e como analista de carreira. Percebe-se que a maioria dos egressos do PPGPsi se encontra inserido no mercado de trabalho, fora os casos que ingressaram no Doutorado para continuidade da formação pós-graduada em Programas localizados no Nordeste brasileiro (CAPES, 2019).

Vale salientar que mesmo sendo um Programa recente, este tem se tornado uma referência no Estado do Piauí, por ser o único Programa de Pós-Graduação em Psicologia, possibilitando não apenas aos psicólogos como também aos profissionais de áreas afins, articular o desenvolvimento científico e a produção do conhecimento que contribui no desenvolvimento de habilidades e competências no âmbito da docência e da pesquisa.

É notório que a chegada do PPGPsi no litoral do Piauí tem contribuído sobremaneira para o aumento das pesquisas científicas e parcerias científico-acadêmicas com instituições nacionais e internacionais com destaque merecido para esta região do Nordeste brasileiro. No entanto, os desafios e dificuldades são constantes quando os apoios para o financiamento da pesquisa são cada vez mais raros na atual conjuntura brasileira, de modo que a motivação e empenho do corpo docente e discente têm sido o diferencial para seguir na consolidação do PPGPsi da UFPI.

Nesses primeiros anos de funcionamento do programa diversas ações de inserção social que o corpo docente do PPGPsi desenvolveu foram registradas: 1) ações em interface a projetos de extensão voltados para área da saúde do idoso, saúde mental e educação popular em saúde junto aos trabalhadores e usuários da rede do município de Parnaíba e circunvizinhos, bem como a promoção de oficinas de direitos junto aos povos tradicionais da região (pescadores artesanais, marisqueiras e mulheres quebradeiras de coco, povos de terreiros); 2) ações em interface com a educação básica na perspectiva de construir programas e políticas para essa área no Piauí: 2.1) com o planejamento, articulação e elaboração de projeto de lei de instituição da semana de luta contra a medicalização da educação e da sociedade junto à Câmaras de Vereadores de pelo menos 19 municípios do Piauí, sancionados em 2017 e 2018; 2.2) construção de programas de formação de professores para os municípios de Parnaíba, Luís Correia e Ilha Grande/PI; 2.3) construção de aplicativo pedagógico do Fórum de Medicalização da educação e da sociedade para profissionais da educação, saúde e assistência social e população geral; 2.4) criação, produção e lançamento do curta metragem infantil sobre "Medicalização da Timidez nas Escolas"; 2.5) construção da "Rede Permanente de Mediação do Clima Escolar" para a Secretaria de Educação do estado do Piauí; 3) composição de comissões locais, regionais e nacionais, a exemplo de: comitês de ética em pesquisa, comitês de programas de iniciação científica; grupo gestor ligado a gerência estadual de saúde mental do Piauí e comissão de análise e Julgamento do prêmio CAPES de tese (edição 2018).

Assim, diante das demandas solicitadas no contexto social ao qual o PPGPsi está inserido, ressalta-se que nestes 24 meses o corpo docente tem buscado pesquisar e colaborar, por meio tanto das dissertações quanto das ações de inserção social (ver Figura 3), para o atendimento destas demandas, conforme demonstra a nuvem de palavras alcançada a partir do banco de Resumos das Dissertações já defendidas e das pesquisas em andamento apresentadas no Seminário de Qualificação em 2018. A referida nuvem de palavras foi alcançada por meio do software IRAMUTEQ (Interface de R pour analyses Multidimensionnelles de Textes et de Questionneires, versão 0.7), o referido programa utiliza a estrutura do software R (www.r-project.org) para realização dos cálculos estatísticos e permite realizar análises quantitativas e qualitativas de dado textuais como, 
por exemplo a nuvem de palavras - análise lexical que permite uma rápida identificação das palavras (Camargo \& Justo, 2013). De acordo com o resultado apresentado é possível perceber o quanto os termos pesquisa, saúde, estudo, Piauí, Psicologia, saúde, análise, expressam a atual realidade dos diversos contextos estudados.

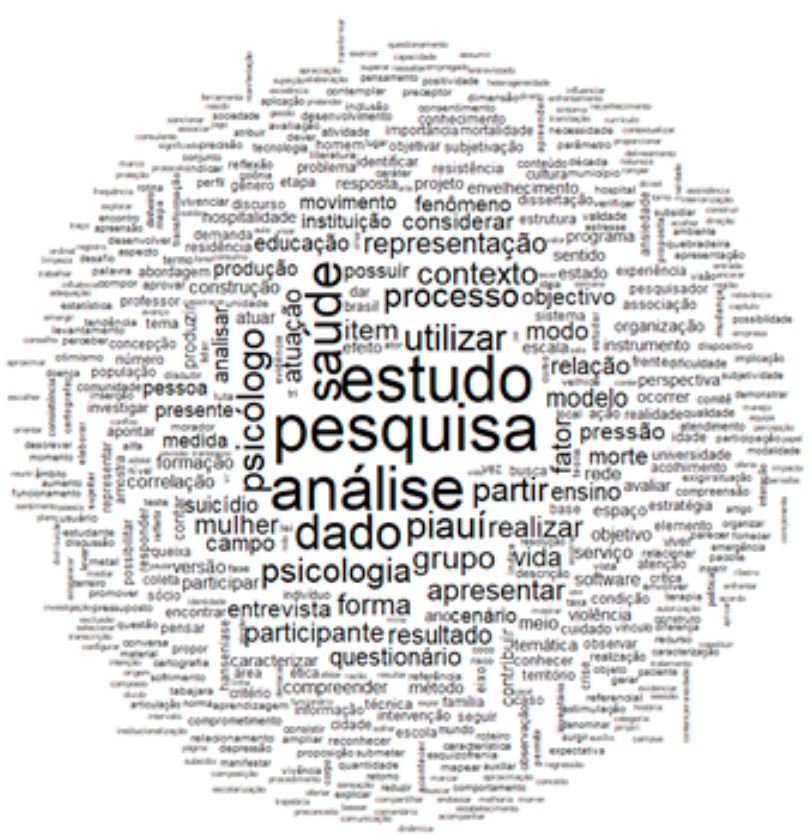

Figura 3. Nuvem de Palavras dos Principais Temas Investigados no PPGPsi/UFPI.

\section{Desafios para fortalecer e consolidar um Programa de Pós-Graduação em Psicologia em contextos periféricos}

Em épocas em que a educação pública, incluindo a de nível superior, passou a ser um dos principais alvos de ataques, cortes e contingenciamento de recursos, por parte do Governo Federal, propor e, especialmente, manter uma Pós-Graduação em Psicologia, em nível de mestrado, fora de um grande centro, em um dos Estados mais pobres do Nordeste brasileiro, não parece ser uma tarefa tentadora. Entretanto, um grupo de 10 docentes, 55 discentes ativos e 13 egressos que fazem o PPGPsi da UFPI, no litoral do Piauí não têm medido esforços e buscam direcioná-los para que o Programa se consolide e possa, em breve, se fortalecer e alçar patamares mais altos de qualidade e impacto social.
Desta forma, o corpo docente do PPGPsi da UFPI tem demostrado esforço, empenho e dedicação para desenvolver suas atividades de pesquisas no âmbito da graduação e pós-graduação com o escopo de contribuir para o desenvolvimento regional e a solidificação da Psicologia enquanto ciência e profissão. No entanto, os desafios são principalmente relativos à falta de financiamento para realização das pesquisas, com o fornecimento de bolsas (iniciação e mestrado) e apoio na aquisição de equipamentos para os núcleos de pesquisa. Apesar disso, o Programa conta atualmente com dois professores do PPGPsi com bolsa de produtividade em pesquisa pelo CNPq e um professor com bolsa produtividade em pesquisa pela própria UFPI - pelo programa de incentivo para professores que tenham sido aprovados em seu mérito, porém, não contemplados por razões de restrições orçamentárias do CNPq. Ressalta-se que outros colegas têm insistido a cada certame para ingressar nesta modalidade de apoio a investigação científica.

Outra dificuldade é quanto ao equilíbrio em relação ao número de professores que compõem as Linhas de Pesquisa do Programa, o que seria importante à realização de concursos direcionados a pós-graduação com escopo de atender a necessidade específica das nossas linhas de pesquisa. Em outra frente seria interessante à inserção de professores visitantes nacionais e estrangeiros, de modo a contribuir com experiências/vivências em termos de pesquisas já consolidadas nos temas objetos do nosso PPGPsi ou do Programa Nacional de Pós-Doutorado - PNPD/ CAPES, dentre outros.

Entende-se que esses desafios também são reflexo da própria estrutura de implantação da educação superior e do Sistema Nacional de Pós-Graduação (SNPG) no país. Sabe-se que a implantação do sistema de ensino superior, no início do século passado (Yamamoto, 2006) e a estruturação da Pós-Graduação e fundação de seus principais fomentadores (CAPES e CNPq) na década de 1950 (Romêo, Romêo, \& Jorge, 2004) são consideradas tardias (Tourinho \& Bastos, 2010). Além disso, as assimetrias regionais da própria Pós-Graduação Brasileira, e na área de Psicologia não foi diferente, foram fatores que também contribuíram para o PPGPsi da UFPI tornar-se realidade apenas em 2017 com a desconcentração espacial do sistema de pós-graduação no Brasil. Deste modo, passa a ser a única possibilidade para aqueles que desejam se qualificar, em 
nível de Mestrado, em Psicologia no estado do Piauí, buscando suprir uma demanda reprimida por décadas. Registra-se, nesse sentido, que em seus quatro processos seletivos executados foram ofertadas 90 vagas e se candidataram 294 postulantes a uma das vagas.

Aliado a este cenário, com impacto direto na engrenagem da Pós-Graduação em Psicologia está o fato do desmembramento do Campus Ministro Reis Veloso e migração da sua estrutura administrativa-acadêmica para a recém-criada Universidade Federal do Delta do Parnaíba (UFDPar). Este fato traz incertezas políticas e econômicas que perdurarão enquanto a UFDPar não nomear o Reitor Pro Tempore e o seu processo de transição não for concluído, pois, apesar de já haver orçamento próprio, na UFDPar ainda não existem Pró-Reitorias de Pesquisa e/ou Pós-Graduação, que deverão ser responsáveis por nortear o gerenciamento das políticas de fortalecimento dos PPG's da nova Instituição de Ensino Superior. Por enquanto, atualmente, o PPGPsi segue sendo gerido pela Pró-Reitoria de Pós-Graduação da UFPI, mas sem a possibilidade de se submeter a suas políticas, a exemplo de editais de fomento discente (isto é, bolsas) ou docente (bolsas de produtividade, recursos para missões de pesquisas e apoio a publicações), pois há o entendimento de que a própria UFDPar é quem deve custear, realidade esta que não acontece até o presente momento.

Outro ponto importante, e que denota uma eminente dificuldade a ser superada, é a falta de incentivo para a dedicação exclusiva do discente para as atividades do PPGPsi. O perfil dos estudantes de Psicologia tem mudado, fazendo com que haja maior heterogeneidade de perfis socioeconômicos dos universitários (Macedo, Alves, Bezerra, \& Silva, 2018), o que deixa claro que cada vez mais serão necessárias políticas de permanência e assistência estudantis mais incisivas que permitam que os estudantes possam finalizar seus estudos sem ter que abandoná-los ou dividir tempo com uma jornada de trabalho.

Na Pós-Graduação não é diferente, tais políticas geralmente se refletem em número de cotas de bolsas de estudo, geralmente mantidas pela CAPES e/ou CNPq. Atualmente, o PPGPsi conta com apenas duas bolsas Demanda Social CAPES, para um montante de 55 discentes ativos. De sorte, que apesar do cenário político-econômico pouco favorável, conta-se com outras 12 bolsas cedidas pela FAPEPI a partir de editais específicos, mas que se encontram próximo do fim de sua vigência e em virtude da conjuntura econômica não existe quaisquer certezas sobre novas edições. Neste sentido, muitos dos discentes, para que possam cursar o Mestrado, precisam estar divididos entre as atividades do Programa e as atividades laborais, o que impacta na qualidade de publicações e inserção social das atividades do PPGPsi, que certamente seriam alavancadas se houvesse um número maior de discentes bolsistas. Outra dificuldade constatada, que pode ser justificado pelo Programa ser recente, é a baixa verba recebida do Programa de Apoio à Pós-Graduação (PROAP), da CAPES, que geralmente custeia parte das atividades corriqueiras de um PPG, o que torna empecilho atividades como convite a docentes de PPG's de outros estados para defesas públicas de dissertações, compra de passagens ou obtenção de diárias pelo corpo docente e/ou discente para ida a eventos científicos, apoio a publicações, etc.

Entretanto, como apontado por Tourinho (2008) e ratificado por Tourinho e Bastos (2010), no que tange a área de Psicologia, ou na maioria delas, as condições para pesquisas e formação de docentes pesquisadores não existem e, muito provavelmente não existirão no cenário que se vislumbram atualmente. Cabem aos integrantes dos Programas de Pós-Graduações, em sua heterogeneidade de linhas e formação, buscar alternativas que diminuam os impactos ou amenizem as dificuldades no processo de produção de conhecimento e qualificação em nível stricto sensu.

Assim, esta tem sido a realidade em que se encontra o PPGPsi da UFPI. O corpo docente, juntamente com representantes discentes, busca traçar metas a médio e longo prazo que permitem perspectivas e expectativas de melhoras, operacionalizado com a composição de uma comissão de planejamento estratégico. Este grupo é responsável por analisar pontos fracos e fortes do Programa e propor melhorias que permitam agregar força aos pontos fortes e sanar os fracos. Por exemplo, nestes dois anos de funcionamento, tornou-se notório a necessidade, e está sendo planejado como será feito, uma reestruturação nas estruturas das duas linhas de pesquisas do PPGPsi, mencionadas anteriormente, para que haja um equilíbrio em termos de componentes das linhas e consequentemente pontuações nos quesitos de avaliação do Sistema Nacional de Pós-graduação (SNPG).

Ademais, este planejamento permite que haja integração maior entre os docentes e discentes no tocante a publicações e ações do Programa, fazendo com que haja maior número de publicações qualificadas, de produtos 
técnicos e ações de inserção social. Registra-se ainda a tentativa de cumprimento dos quesitos básicos para inclusão na fórmula de rateio das verbas PROAP e distribuição de bolsas que venham a estar disponíveis. Sendo que também é possível perceber que são traçados planos para eventos do PPGPsi que busca integralizar a comunidade e, em particular a graduação e a pós-graduação, fazendo com que o papel social destas ações seja potencializado. Além do próprio esforço de articulação dos docentes do Programa com grupos/núcleos de pesquisa com outros PPG's do Nordeste brasileiro e do país, fortalecendo redes de pesquisa nacionais e internacionais.

Portanto, acredita-se que o Programa de Pós-Graduação em Psicologia da Universidade Federal do Piauí está em direção ao planejado, ou seja, seus integrantes trabalham com o objetivo claro para que haja a possibilidade de ser avaliado pelo SNPG/CAPES positivamente, se possível elevando num futuro próximo o conceito do curso para nota 4 na recomendação da CAPES. Será possível? Só o tempo poderá responder, mas frente a todos os desafios enfrentados e que ainda se apresentarão, estima-se que haja força de trabalho humana capaz de vencê-los e somado a atividades planejadas com antecedência e com exequibilidade garantida, institucionalmente falando, são expectativas que podem ser concretizadas em curto/médio prazo.

Por fim, acrescenta-se que é clara a busca do PPGPsi do litoral piauiense, em contribuir com o Plano Nacional de Pós-Graduação 2011-2020 (PNPG), que passou por diversas mudanças ao longo dos anos, refletindo a necessidade de ampliar o crescimento e qualidade da Pós-Graduação e o seu desafio de elevar a pós-graduação brasileira alcançar os índices das grandes potências. Em nível micro (político, econômico e regional), quando se pensa em âmbito nacional, cumpre-se bem este objetivo, já que o fato de se tentar manter uma Pós-Graduação, com qualidade, é de fundamental importância para o desenvolvimento de uma nação, estado, município. Afinal, capacitar mão de obra altamente qualificada, compromissada com as dimensões ético-políticas de seu contexto, é contribuir para refletir e construir um melhor contexto socioeconômico e político.

\section{Referências}

Alves, M. F., \& Oliveira, J. F.D. (2014). Pós-Graduação no Brasil: do Regime Militar aos dias atuais. Revista Brasileira de Política e Administração da Educação, 30(1), 351-376. doi: 10.21573/vol30n22014.53680
Câmara dos Deputados (2018). Projeto de lei n. 6 de 2018. Cria a Universidade Federal do Delta do Parnaíba, por desmembramento da Universidade Federal do Piauí. Senado Federal:Brasília, DF: Câmara dos Deputados. Recuperado de https://legis.senado.leg.br/sdleg-getter/ documento?dm=7629516\&ts=1567527363209\&disposition=inline

Camargo, B. V., \& Justo, A. M. (2013). IRAMUTEQ: um software gratuito para análise de dados textuais. Temas em Psicologia, 21(2), 513-518. doi: 10.9788/TP2013.2-16

Coordenação de Aperfeiçoamento de Pessoal de Nível Superior CAPES (2019). Relatório do Seminário de Acompanhamento (ou Seminário de Meio Termo) apresentado pela Coordenação da Área da Psicologia. Brasília, DF: Autor.

Coordenação de Aperfeiçoamento de Pessoal de Nível Superior - CAPES (2018). Aprovação e Recomendação do Programa de Pós-Graduação em Psicologia pela CAPES por meio da $166^{\underline{a}}$ Reunião do CTC. Brasília, DF: Autor.

Coordenação de Aperfeiçoamento de Pessoal de Nível Superior - CAPES (2016). Relatório de Avaliação Quadrienal (2012-2016) apresentado pela Coordenação da Área da Psicologia. Brasília, DF: Autor.

Féres-Carneiro, T., Bastos, A. V., Feitosa, M. A. G., Seidl-de-Moura, M. L., \&Yamamoto, O.H. (2010). Lacunas, metas e condições para a expansão da pós-graduação em psicologia no país. Psicologia: Reflexão e Crítica, 23(Suppl. 1), 11-24. doi: 10.1590/S0102-79722010000400003

Macedo, J.P., Alves, C.S., Bezerra, L. L. S., \& Silva, J.R.(2018).A "popularização" do perfil dos estudantes de Psicologia no Brasil. Arquivos Brasileiros de Psicologia, 70(2), 81-95. Recuperado de http://pepsic.bvsalud.org/ scielo.php?script=sci_arttext\&pid=S1809-52672018000200007\&lng= pt\&tlng=pt

Romêo, J. R. M., Romêo, C. I. M., \& Jorge, V. L. (2004). Estudos de pós-graduação no Brasil. In Instituto Internacional para la Educación Superior en la América Latina y el Caribe \& Organização das Nações Unidas para a Educação, a Ciência e a Cultura, Reunión Regional sobre el Diagnóstico y la Perspectiva de los Estudios de Posgrado en America Latina (pp. 1-76). São Paulo, SP: Instituto Internacional para la Educación Superior en la América Latina y el Caribe. Recuperado de http://www.iesalc.unesco.org.ve/programas/Postgrados

Tourinho, E. Z. (2008). Editorial. Revista Latinoamericana de Psicopatologia Fundamental, 11(3), 361-364. doi: 10.1590/ S1415-47142008000300001

Tourinho, E. Z., \& Bastos, A. V.B. (2010). Desafios da Pós-Graduação em Psicologia no Brasil. Psicologia: Reflexão e Crítica, 23(Supl 1), 35-46. doi: 10.1590/S0102-79722010000400005

Universidade Federal do Piauí - UFPI (2015). Plano de Desenvolvimento Institucional-PDI. Aprovado pela Resolução Conjunta do Conselho Diretor - CONSUN no 002/2015. Teresina, PI: UFPI. Recuperado de https://ufpi.br/arquivos_download/arquivos/PROPLAN/pdi/PDI--20152019_UFPI_Reformulado_Versao-Final.pdf

Universidade Federal do Piauí - UFPI (2016). Proposta de Criação do Programa de Pós-Graduação em Psicologia. Aprovado pela Resolução do CEPEX da UFPI no 073/2016. Teresina, PI: UFPI. Recuperado de https://www.ufpi.br/images/213.pdf

Yamamoto, O. H. (2006). Graduação e pós-graduação em Psicologia: relações possíveis. Revista Brasileira de Pós-Graduação, 3(6), 270-281. doi: 10.21713/2358-2332.2006.v3.110 
Ludgleydson Fernandes de Araújo, Doutor em Psicologia pela Universidad de Granada, Espanha, é Docente da Universidade

Federal do Delta do Parnaíba - UFDPAR. Endereço para correspondência: Universidade Federal do Delta do Parnaíba/

Programa de Pós-Graduação (Stricto Sensu) em Psicologia.

Av. São Sebastião, 2819, Parnaíba. CEP: 64.202-020

Telefone. + 55 (86) 3323-5418. Email: ludgleydson@yahoo.com.br

Emerson Diógenes de Medeiros, Doutor e Pós Doutor em Psicologia Social pela Universidade Federal da Paraíba - UFPB, é Docente da Universidade Federal do Delta do Parnaíba - UFDPAR. Email: emersondiogenes@gmail.com

Fauston Negreiros, Doutor em Educação pela Universidade Federal do Ceará - UFC, Pós-Doutor em Psicologia Escolar e Desenvolvimento pela Universidade de São Paulo - USP, é Docente da Universidade Federal do Delta do Parnaíba - UFDPAR. Email: faustonnegreiros@ufpi.edu.br

João Paulo Macedo, Doutor em Psicologia pela Universidade Federal do Rio Grande do Norte - UFRN, é Docente da Universidade Federal do Delta do Parnaíba - UFDPAR. Email:.jpmacedo@ufpi.edu.br

Paloma Cavalcante Bezerra de Medeiros, Doutora em Psicologia Social pela Universidade Federal da Paraíba - UFPB, é Docente da Universidade Federal do Delta do Parnaíba - UFDPAR. Email: palomacbmedeiros@gmail.com

Raquel Pereira Belo, Doutora em Psicologia Social pela Universidade Federal da Paraíba - UFPB, é Docente da Universidade Federal do Delta do Parnaíba - UFDPAR. Email: rbelo@ufpi.edu.br

Sandra Elisa de Assis Freire, Doutora em Psicologia Social pela Universidade Federal da Paraíba - UFPB, é Docente da Universidade Federal do Delta do Parnaíba - UFDPAR. Email: sandraelisa.freire@gmail.com 